\title{
Removal of Zn (II) and Cu (II) Ions from Industrial Wastewaters Using Magnetic Biochar Derived from Water Hyacinth
}

\author{
Benias C. Nyamunda $\left(\mathbb{D},{ }^{1}\right.$ Terrence Chivhanga, ${ }^{1}$ Upenyu Guyo $\mathbb{D}^{2},{ }^{2}$ and Fidelis Chigondo ${ }^{2}{ }^{2}$ \\ ${ }^{1}$ Manicaland State University of Applied Sciences, P. Bag 7001 Mutare, Zimbabwe \\ ${ }^{2}$ Midlands State University, P. Bag 9055 Gweru, Zimbabwe \\ Correspondence should be addressed to Benias C. Nyamunda; nyamundab@gmail.com
}

Received 11 February 2019; Revised 12 April 2019; Accepted 2 May 2019; Published 15 May 2019

Academic Editor: Runcang Sun

Copyright (c) 2019 Benias C. Nyamunda et al. This is an open access article distributed under the Creative Commons Attribution License, which permits unrestricted use, distribution, and reproduction in any medium, provided the original work is properly cited.

\begin{abstract}
This study evaluates the effectiveness of magnetic biochar $\left(\mathrm{Fe}_{2} \mathrm{O}_{3}\right.$-EC) derived from water hyacinth in the removal of $\mathrm{Cu}^{+2}$ and $\mathrm{Zn}^{+2}$ from aqueous solution. $\mathrm{Fe}_{2} \mathrm{O}_{3}$-EC was prepared by chemical coprecipitation of a mixture of $\mathrm{FeCl}_{2}$ and $\mathrm{FeCl}_{3}$ on water hyacinth biomass followed by pyrolysis. The adsorbent was characterized by Fourier transform infrared spectroscopy (FTIR) and scanning electron microscopy (SEM) coupled with energy dispersive spectroscopy (EDX). Batch adsorption studies on the effects of temperature, biosorbent dosage, contact time, and initial metal ion concentration were carried out. $\mathrm{Fe}_{2} \mathrm{O}_{3}$-EC exhibited optimum contact time, biosorbent dosage, and $\mathrm{pH}$ values of $65 \mathrm{~min}, 1.2 \mathrm{~g}$, and 6, respectively. $\mathrm{Fe}_{2} \mathrm{O}_{3}$-EC exhibited strong magnetic separation ability and high sorption capability. Metal ion adsorption onto the biochar conformed to the Langmuir isotherm. Kinetic studies revealed that the adsorption process followed pseudo-second-order model. The calculated thermodynamic parameters showed that the adsorption process was feasible and exothermic in nature. These results have demonstrated that the use of $\mathrm{Fe}_{2} \mathrm{O}_{3}-\mathrm{EC}$ in metal ion removal could provide an alternative way to manage and utilize this highly problematic invasive species.
\end{abstract}

\section{Introduction}

Rapid increase in human industrial activities such as agriculture, mining, and manufacturing has resulted in discharge of heavy metal contaminated wastewaters $[1,2]$ into main water bodies. The nonbiodegradability of toxic heavy metals results in their bioaccumulation in aquatic plants and animals $[3,4]$. Among toxic heavy metal pollutants, zinc and copper are often present in industrial wastewaters. These heavy metals originate from various industrial processes such as electroplating, textile, photographic materials, painting, galvanizing, battery, paper, and explosives manufacturing [5]. There is need to develop efficient and cost effective ways of removing heavy metal contaminants from industrial wastewaters.

Several industrial wastewater techniques such as ion exchange, solvent extraction, chemical precipitation, and activated carbon adsorption are usually applied to remove heavy metal pollutants [6-8]. However these technologies suffer drawbacks of incomplete pollutant removal, high reagent or energy requirements, and toxic sludge generation
[9]. Biosorption has been reported as an emerging, effective, competitive, and inexpensive technology because of its high efficiency and easy handling nature for heavy metal ion removal [10]. Adsorption of heavy metals on surface of biomaterials occurs through different functional groups such as amino, carboxyl, hydroxyl, phenolic, ester, sulfhydryl, and phosphate [9]. Several plant based biosorbents have been used for the removal of heavy metal pollutants from wastewaters [10-13]. These include eucalyptus bark [14], bush mango [15], lignocellulose [16], marula [17], rice husk [18], and switchgrass [19]. Huge volumes of polluted industrial wastewaters still demand exploration of newer adsorbents.

Water hyacinth (Eichhornia Crassipes) is ranked amongst the most prevalent aquatic weeds exhibiting global adverse effects on aquatic ecosystems [20,21]. The renowned impact of uncontrolled growth of water hyacinth includes disruption of water abstraction facilities and blockage of irrigation networks $[22,23]$. The weed is also a favourable breeding ground for health hazard vectors such as mosquitos and bilharzia snails. 
To overcome problems associated with water hyacinth, several weed management methods such as physical removal, chemical application of herbicides, and use of biological control agents have been adopted [24]. However these methods are expensive, ineffective, and labour and energy intensive [25-27].

Although water hyacinth is responsible for numerous challenges, it has found wide ranging useful applications as a phytoremediation agent of industrial wastewaters [28]. One effective way for improved management of this highly invasive species involves conversion of water hyacinth into biochar for the treatment of industrial effluents.

Biochar is a carbon-rich product derived from pyrolysis of biomass with little oxygen. Compared to activated carbon, biochar pyrolysed at temperatures not more than $700^{\circ} \mathrm{C}$ has been demonstrated to possess higher functional groups and mineral ash [29] rendering it a potential environmental sorbent for various ionic pollutants [30-32]. Biochar is a promising low cost adsorbent for metal ion removal from industrial wastewaters. Its application however is limited by low metal sorption capacities [33]. To enhance metal sorption capacities, biochars have been modified by loading with minerals, organic functional groups, reductants, nanoparticles, and alkali solution [34].

The use of biochar derived from hyacinth in the removal of phosphates [35], arsenate [36], cadmium [37], and chromium [38] has been reported in literature. Coprecipitation of iron salts on water hyacinth followed by pyrolysis improved potential of the biochar for efficient removal of these ionic pollutants. However to the best of our knowledge no study has been reported for the use of hyacinth biochar in the removal of $\mathrm{Cu}^{+2}$ and $\mathrm{Zn}^{+2}$ from wastewaters.

This study evaluates the effectiveness of biochar derived from water hyacinth in removing $\mathrm{Cu}^{+2}$ and $\mathrm{Zn}^{+2}$ from aqueous solution. An investigation of the kinetics and isotherm studies of these metal ions for the biochar sorption will be done.

\section{Method}

2.1. Preparation of Biosorbent. Water hyacinth was collected from Lake Chivero located about $22 \mathrm{~km}$ south of Harare, Zimbabwe. The water hyacinth sample was chopped followed by drying in sunlight for 5 days. The samples were further dried in an oven set at $100^{\circ} \mathrm{C}$ for $24 \mathrm{~h}$. The dried material was ground and sieved to produce particles in size range $0.25-1.75 \mathrm{~mm}$. Ground water hyacinth samples were kept in an air tight container. The dried biomass $(200 \mathrm{~g})$ was saturated in $1000 \mathrm{~mL}$ aqueous equimolar $(2 \mathrm{M})$ mixture of $\mathrm{FeCl}_{2}$ and $\mathrm{FeCl}_{3}$. Under vigorous magnetic stirring, $5 \mathrm{M} \mathrm{NaOH}$ solution was added dropwise to increase the suspension $\mathrm{pH}$ to 10 . The mixture was subjected to continuous stirring for $30 \mathrm{~min}$ prior to separation by centrifugation at $3000 \mathrm{rpm}$ for 10 min. A ceramic pot was tightly filled with the biomass. The full pot was covered with a lid prior to pyrolysis. During pyrolysis, the biomass was initially heated to $100^{\circ} \mathrm{C}$ for $2 \mathrm{~h}$. This was followed by heating at a rate of $5^{\circ} \mathrm{C}$ per min to attain three maximum temperatures $\left(200,300\right.$, and $\left.600^{\circ} \mathrm{C}\right)$ and continuing heating for $6 \mathrm{~h}$. The pyrolysed products were cooled to room temperature followed by grinding and sieving to produce uniform particle sizes $(250 \mu \mathrm{m})$. The biochar particles were rinsed with deionized distilled water several times to remove most organic matter. The saturated biomass was then dried in an oven.

2.2. Characterisation of Biochar. Physisorption measurements of $\mathrm{Fe}_{2} \mathrm{O}_{3}$-EC and EC were carried out using Micromeritics ASAP 2020 surface area and porosity analyzer. Samples $(0.05 \mathrm{~g})$ were degassed to eliminate any carbon dioxide and water, so that a clean surface was obtained. The samples were then submitted to physisorption analysis for $12 \mathrm{~h}$. Analyses of the superficial element composition of $\mathrm{Fe}_{2} \mathrm{O}_{3}$-EC and imaging of the surface morphology were done on a scanning electron microscope (SEM) using a JEOL7500 field emission electron microscope at $20 \mathrm{keV}$. Attached to it was an energy dispersive X-ray spectrometer (EDX). The samples were mounted onto metal stubs with double sided carbon tape before imaging. The FTIR of the adsorbent were obtained using Thermofisher Scientific spectrometer (Nicolet 6700, USA) in the frequency range $500-4000 \mathrm{~cm}^{-1}$. Magnetisation curve of biochars was obtained using PPMS 9T vibrating sample magnetometer (Quantum design, USA) at room temperature under applied field range -15000 to 15000 Oe.

2.3. Batch Adsorption Experiments. Stock solutions (1000 $\mathrm{mg} \mathrm{L}^{-1}$ ) of $\mathrm{Cu}^{+2}$ and $\mathrm{Zn}^{+2}$ were prepared by dissolving appropriate amounts of nitrate precursor salts (Sigma, South Africa) in deionized water and acidified with concentrated $\mathrm{HNO}_{3}(5 \mathrm{~mL})$. Biosorption experiments were carried out in tightly closed $250 \mathrm{~mL}$ Erlenmeyer flasks containing $100 \mathrm{~mL}$ of separate metal ion solutions. The flasks containing $1 \mathrm{~g}$ biochar were continuously agitated $(150 \mathrm{rpm})$ at room temperature on a shaker for $2 \mathrm{~h}$. The resultant solutions were filtered on Whatman 42 filter paper, and the supernatant liquid was analyzed on a flame atomic absorption spectrometer (FAAS), Shimadzu AA-680, Japan. The percentage of metal ion removal was calculated using

$$
R=\frac{\left(C_{o}-C_{e}\right) 100}{C_{o}}
$$

The biosorption efficiency was calculated according to the following equation:

$$
q_{e}=\frac{\left(C_{o}-C_{e}\right) V}{M}
$$

where $\mathrm{q}_{\mathrm{e}}$ is the amount ( $\mathrm{mg} \mathrm{g}^{-1}$ ) of metal ion adsorbed by biochar, $\mathrm{C}_{\mathrm{o}}$ and $\mathrm{C}_{\mathrm{e}}$ are the metal ion concentrations $\left(\mathrm{mg} \mathrm{L}^{-1}\right)$ in the solution initially and after biosorption, respectively, $\mathrm{V}$ is the volume (L) of the solution, and $\mathrm{m}$ is the mass (g) of biosorbent. The influence of $\mathrm{pH}$ on the removal of metal ions was monitored in the $\mathrm{pH}$ range $2-10 . \mathrm{pH}$ adjustments were done using aqueous $\mathrm{NaOH}$ or $\mathrm{HCl}$. The effects of other parameters on metal ion adsorption were monitored at different parameter ranges: temperature (25$50^{\circ} \mathrm{C}$ ), biosorbent dosage (0.2-2 g), contact time (30-125 $\left.\mathrm{min}\right)$, and initial metal ion concentration (20-100 $\left.\mathrm{mg} \mathrm{L}^{-1}\right)$. 


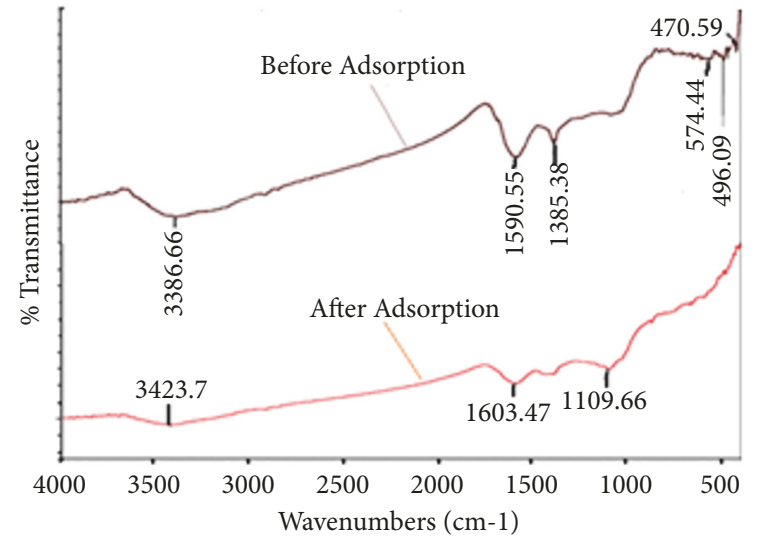

(a)

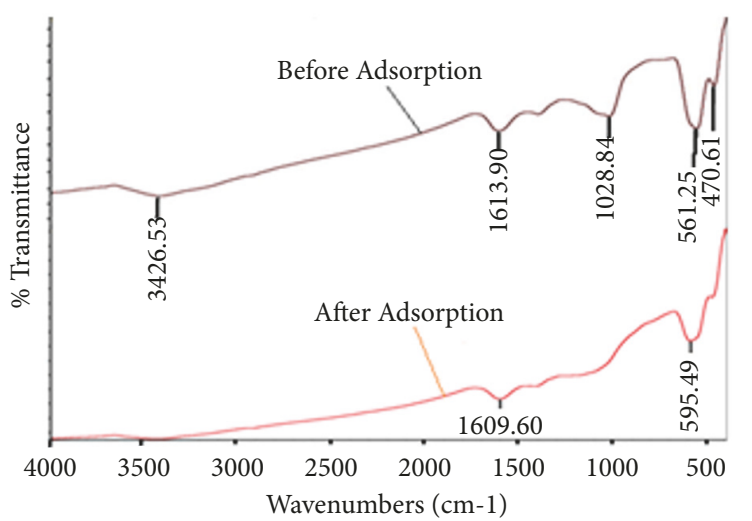

(b)

FIGURE 1: FTIR spectrum for adsorbed and unadsorbed biochars: (a) EC, (b) $\mathrm{Fe}_{2} \mathrm{O}_{3} \mathrm{EC}$.

TABLE 1: Specific surface areas of EC and $\mathrm{Fe}_{2} \mathrm{O}_{3}$-EC.

\begin{tabular}{lcc}
\hline Temperature $\left({ }^{\circ} \mathrm{C}\right)$ & Adsorbent & Surface area $\left(\mathrm{m}^{2} \mathrm{~g}^{-1}\right)$ \\
\hline \multirow{2}{*}{350} & $\mathrm{EC}$ & 150.13 \\
& $\mathrm{Fe}_{2} \mathrm{O}_{3}-\mathrm{EC}$ & 163.60 \\
\hline \multirow{2}{*}{450} & $\mathrm{EC}$ & 610.88 \\
& $\mathrm{Fe}_{2} \mathrm{O}_{3}$-EC & 1038.48 \\
\hline \multirow{2}{*}{600} & $\mathrm{EC}$ & 553.59 \\
& $\mathrm{Fe}_{2} \mathrm{O}_{3}-\mathrm{EC}$ & 983.75 \\
\hline
\end{tabular}

2.4. Desorption and Reusability Studies. Biosorbent samples $(1.2 \mathrm{~g})$ of $\mathrm{Fe}_{2} \mathrm{O}_{3}$-EC and EC were contacted with $100 \mathrm{~mL}$ aqueous solutions of $15 \mathrm{mg} \mathrm{L}^{-1} \mathrm{Cu}^{+2}$ or $\mathrm{Zn}^{+2}$ at $25^{\circ} \mathrm{C}$ and $\mathrm{pH}$ 6 for $65 \mathrm{~min}$. After metal ion sorption, the adsorbents were filtered and washed thrice with deionized water to remove residual metal ions on surface. The adsorbents were then kept in contact with $100 \mathrm{~mL} \mathrm{NaOH}$ solutions (0.1-0.5 M) to desorb metal ions. The mixtures were shaken on a rotary shaker for $15 \mathrm{~min}$. The filtrates were analyzed for metal ion content on FAAS.

\section{Results}

3.1. Characterisation of the Adsorbent. Table 1 shows the specific surface areas of $\mathrm{Fe}_{2} \mathrm{O}_{3}$-EC and EC at different pyrolysis temperatures. Surface areas of EC were smaller than those of $\mathrm{Fe}_{2} \mathrm{O}_{3}$-EC. This could be attributed to $\mathrm{Fe}_{2} \mathrm{O}_{3}$-EC containing considerable proportion of iron oxide particles, which have small surface areas and abundant transitional pores [39]. For both adsorbents, an increase in surface area with increasing temperature was observed due to volatilization of transitional fluxes (secondary reactions) presented by the thermal decomposition of the biomass cellulosic and semicellulosic structures [40]. These secondary reactions become prominent with increasing temperature resulting in continued cracking of the biomass structure forming voids on the surface. However, as temperature was further increased beyond $500^{\circ} \mathrm{C}$, there was a notable decrease in surface area due to collapse of the overall mesoporous structure of the adsorbents as a result of volatilization of most of the biomass inorganic binding sites [40].

The formation of iron oxides could be explained by the fact that during pyrolysis the ferric chloride underwent drastic dehydration process forming $\mathrm{Fe}_{3} \mathrm{O}_{4}$ through an overall reaction [41]: $\mathrm{Fe}^{+2}+2 \mathrm{Fe}^{+3}+8 \mathrm{OH}^{-} \longrightarrow \mathrm{Fe}_{3} \mathrm{O}_{4}$.

This process is accompanied by release of volatile gases such as $\mathrm{HCl}$, water, and carbon dioxide.

FTIR spectra of EC and $\mathrm{Fe}_{2} \mathrm{O}_{3}$-EC before and after $\mathrm{Zn}^{+2}$ sorption are shown in Figure 1. EC spectrum showed a prominent peak at $1385 \mathrm{~cm}^{-1}$ which is absent in $\mathrm{Fe}_{2} \mathrm{O}_{3}$-EC. A peak at $1028 \mathrm{~cm}^{-1}$ was observed on $\mathrm{Fe}_{2} \mathrm{O}_{3}$-EC spectrum which is absent on EC. A strong peak at $561 \mathrm{~cm}^{-1}$ was attributed to $\mathrm{Fe}-\mathrm{O}$ lattice vibrations of $\mathrm{Fe}_{3} \mathrm{O}_{4}[36,39,42,43]$ confirming loading of iron oxide onto the biochar. The $\mathrm{OH}$ vibrations were observed at $3300-3500 \mathrm{~cm}^{-1}$ while peaks at around $1590-1614 \mathrm{~cm}^{-1}$ were attributed to aromatic $\mathrm{C}=\mathrm{C}$ and $\mathrm{C}=\mathrm{O}$ vibrations. The band at $1385 \mathrm{~cm}^{-1}$ is characteristic symmetric CO stretching vibrations. Upon $\mathrm{Zn}^{+2}$ adsorption the peaks on EC at $3386 \mathrm{~cm}^{-1}(\nu \mathrm{O}-\mathrm{H})$ and $1590 \mathrm{~cm}^{-1}(\nu \mathrm{C}=\mathrm{O})$ shifted to $3423 \mathrm{~cm}^{-1}$ and $1603 \mathrm{~cm}^{-1}$, respectively. There was disappearance of peak at $1385 \mathrm{~cm}^{-1}$ on EC and emergency of a new peak at $1109 \mathrm{~cm}^{-1}$ upon $\mathrm{Zn}^{+2}$ adsorption. The peak at $1028 \mathrm{~cm}^{-1}$ disappeared and a shift in peak from 561 to 595 $\mathrm{cm}^{-1}$ was observed on loaded $\mathrm{Fe}_{2} \mathrm{O}_{3}$-EC. Emergence of a new peak at $1110 \mathrm{~cm}^{-1}$ was observed on $\mathrm{Zn}^{+2}$ loaded EC. The FTIR spectra for the $\mathrm{Zn}^{+2}$ or $\mathrm{Cu}^{+2}$ loaded onto the biosorbents were almost similar showing that similar functional groups might have been involved in biosorption.

The magnetisation characteristics of $\mathrm{EC}$ and $\mathrm{Fe}_{2} \mathrm{O}_{3}$-EC were done and responses are shown in Figure 2. EC showed no magnetic response while $\mathrm{Fe}_{2} \mathrm{O}_{3}$-EC was strongly attracted to the magnet. After submerging $\mathrm{Fe}_{2} \mathrm{O}_{3}$-EC in water for 2 weeks, the biosorbent retained excellent magnetic properties. The stability of $\mathrm{Fe}_{2} \mathrm{O}_{3}$-EC was tested by immersing samples in highly acidic and basic media at pH 2 and 12, respectively for 


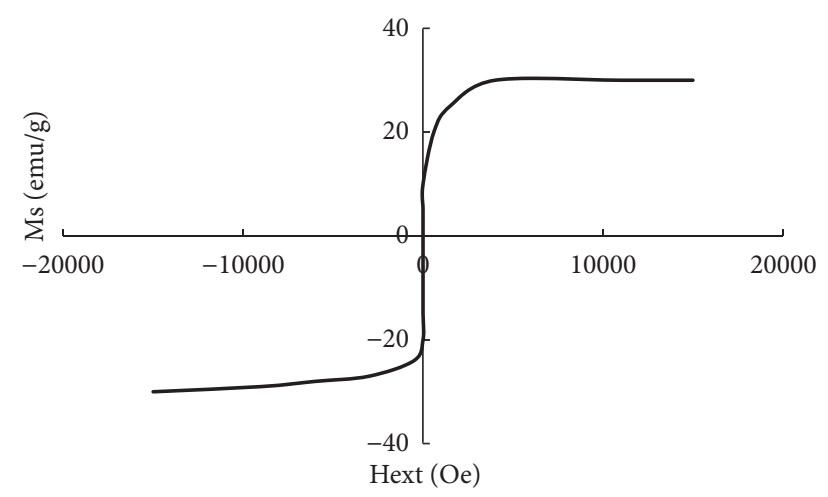

Figure 2: Magnetic response of $\mathrm{Fe}_{2} \mathrm{O}_{3}$-EC.

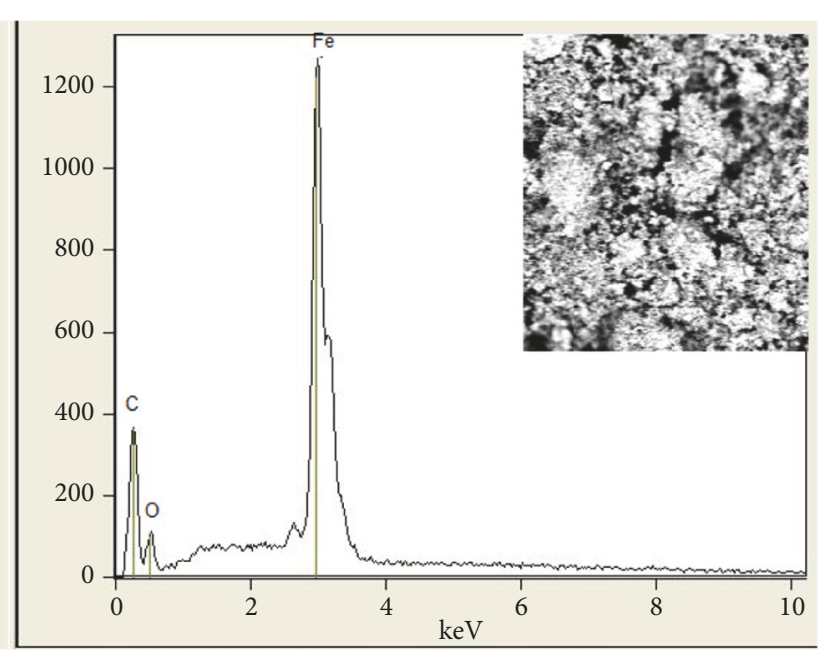

Figure 3: SEM-EDX of $\mathrm{Fe}_{2} \mathrm{O}_{3}$-EC.

2 days. Subjecting the supernatant to the magnet showed no detectable ions confirming that iron was strongly bound in the biosorbent matrix.

SEM-EDX of $\mathrm{Fe}_{2} \mathrm{O}_{3}$-EC is shown in Figure 3. The EDS spectrum confirmed the predominance of iron and oxygen, accounting for more than 70\% (atomic ratio) of the total surficial elements. Carbon was also detected on the adsorbent surface by EDS. $\mathrm{Fe}_{2} \mathrm{O}_{3}$-EC exhibited an irregular rough surface that can provide binding sites for metal ions.

\subsection{Batch Adsorption Studies}

3.2.1. Effect of $p H$. Solution $\mathrm{pH}$ is one crucial parameter that has a bearing on surface ionization of adsorbent functional groups and metal ion speciation [44, 45]. The effect of $\mathrm{pH}$ on $\mathrm{Zn}^{+2}$ and $\mathrm{Cu}^{+2}$ removal is shown in Figure 4. The maximum metal ion adsorption was observed at $\mathrm{pH} 6$. Higher values for adsorption were observed using $\mathrm{Fe}_{2} \mathrm{O}_{3}$ EC. Incorporation of iron oxide particles in the biochar introduces more sorption sites via electrostatic interactions [46]. Maximum adsorption efficiencies on $\mathrm{Fe}_{2} \mathrm{O}_{3}$-EC were $92 \%$ and $79.6 \%$ for $\mathrm{Cu}^{+2}$ and $\mathrm{Zn}^{+2}$, respectively. EC attained maximum adsorption efficiencies of $66.1 \%$ and $78.8 \%$ for

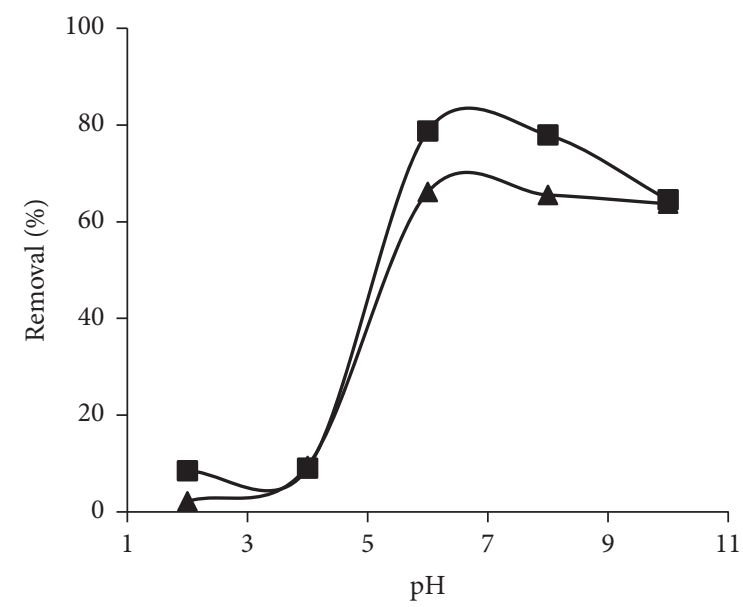

(a)

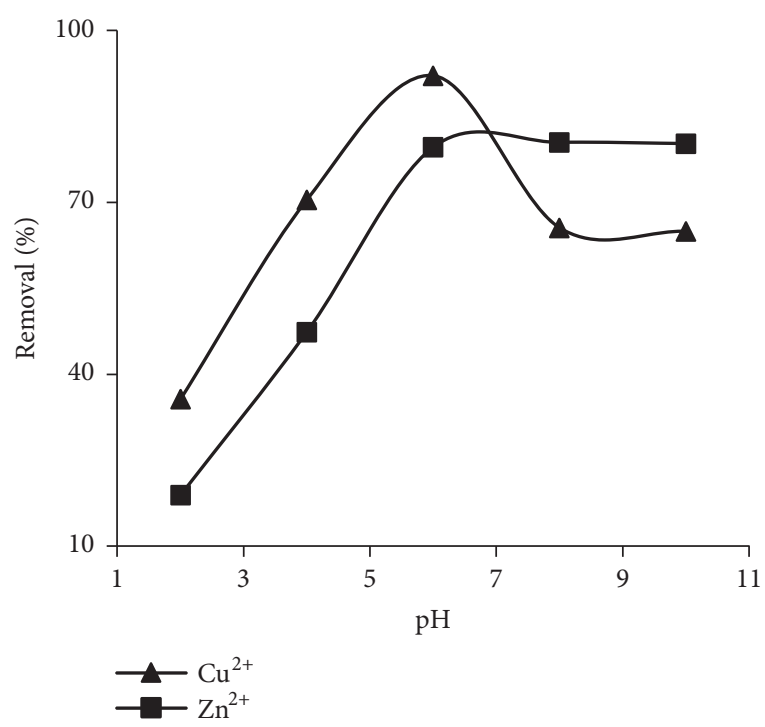

(b)

FIGURE 4: Effect of $\mathrm{pH}$ on metal ion removal using (a) EC and (b) $\mathrm{Fe}_{2} \mathrm{O}_{3}$-EC.

$\mathrm{Cu}^{+2}$ and $\mathrm{Zn}^{+2}$, respectively. At low $\mathrm{pH}$, hydroxonium and metal ions compete for adsorption sites [47]. The biosorbent surface becomes more negative with increasing $\mathrm{pH}$ making it more readily available for metal ion adsorption. Beyond optimum $\mathrm{pH}$ a decrease in metal ion adsorption was observed due to formation of soluble metal ion complexes.

3.2.2. Effect of Contact Time. The effect of contact time on metal ion adsorption is shown in Figure 5. The metal ion removal efficient was high during initial stages. This could be attributed to adsorption of metal ions onto the exterior surface of the biochar and the availability of more vacant surface binding sites [48]. This was followed by gradual metal ion uptake due to ions diffusing into the interior surface before levelling off beyond $65 \mathrm{~min}$ as a result of saturation and repulsion between the adsorbed species and the bulk phases 


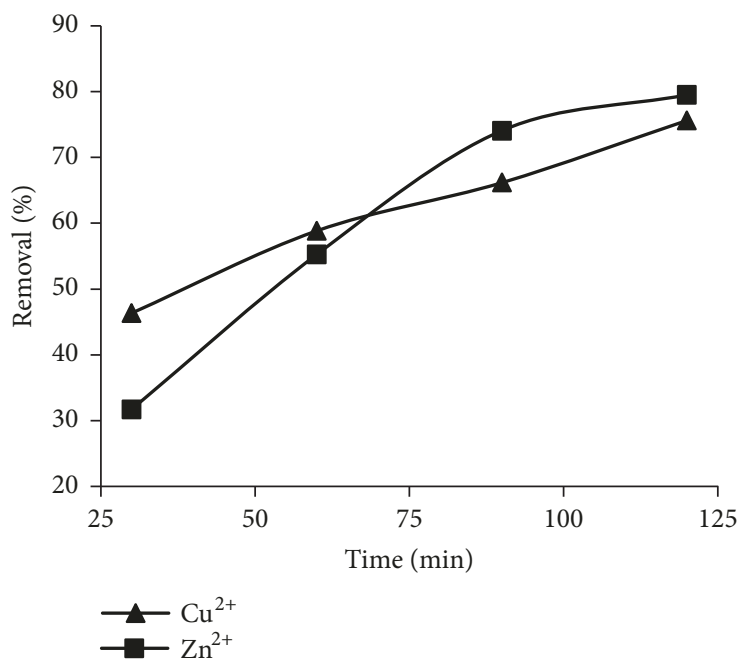

(a)

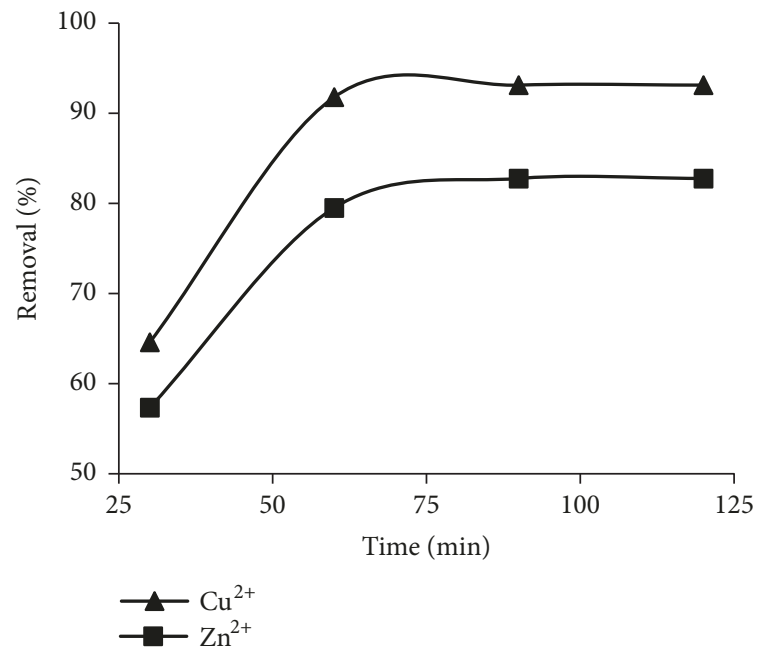

(b)

FIGURE 5: Effect of contact time on metal ion removal using (a) EC and (b) $\mathrm{Fe}_{2} \mathrm{O}_{3}$-EC.

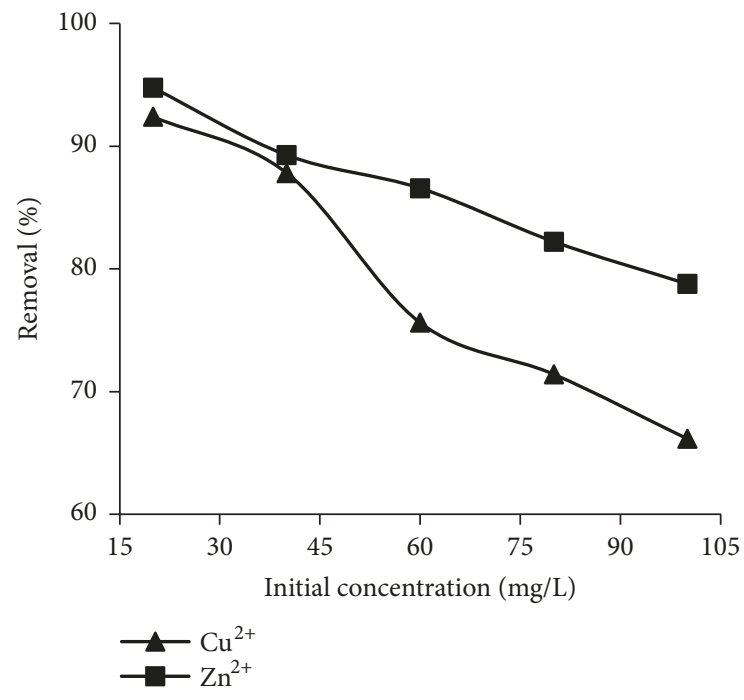

(a)

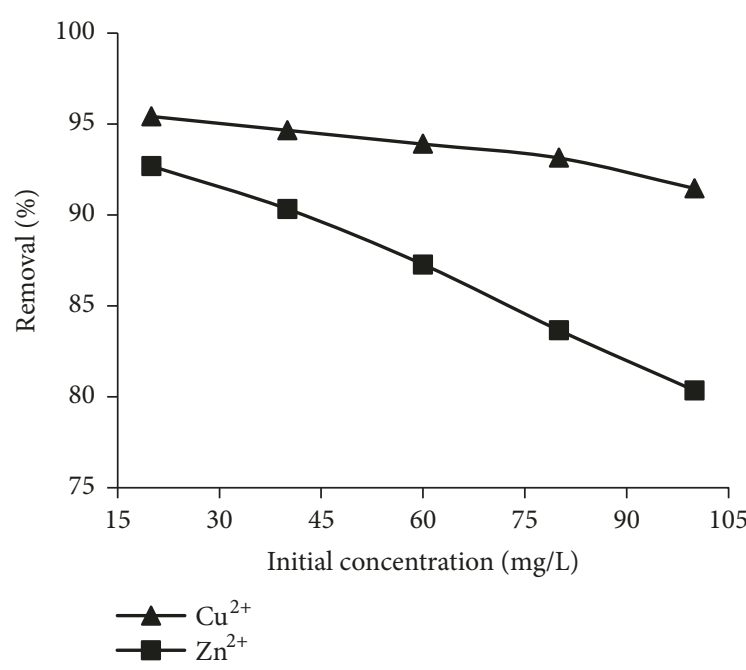

(b)

FIGURE 6: Effect of initial metal ion concentration on pollutant removal using (a) EC and (b) $\mathrm{Fe}_{2} \mathrm{O}_{3}$-EC.

$[49,50] . \mathrm{Fe}_{2} \mathrm{O}_{3}$-EC gave a maximum adsorption efficiency of $79.5 \%$ and $91.8 \%$ for $\mathrm{Zn}^{+2}$ and $\mathrm{Cu}^{+2}$, respectively. $\mathrm{EC}$ exhibited longer saturation contact time of more than $100 \mathrm{~min}$ giving maximum adsorption efficiency for $\mathrm{Zn}^{+2}$ and $\mathrm{Cu}^{+2}$ of $74.1 \%$ and $66.2 \%$, respectively.

3.2.3. Effect of Initial Metal Ion Concentration. Figure 6 shows the effect of initial metal ion concentration on adsorption. A decrease in adsorption efficiency was observed with increasing initial metal ion concentration. At low metal ion concentration most of the metal ions in solution are adsorbed onto vacant active sites of the biosorbent resulting in significantly high metal ion adsorption efficiency [9]. As the initial metal ion concentration increases active sites become saturated leaving most metal ions in solution. Similar trends were previously reported using other biosorbents [17].

3.2.4. Effect of Adsorbent Dosage. According to Sari and Tuzen [51], biosorbent dosage determines the pollutant removal capacity for a given initial concentration. The effect of biosorbent dosage on metal ion removal is shown in Figure 7. The metal ion removal efficient increased with increasing biomass dosage until it levelled off at $1.2 \mathrm{~g}$. Maximum metal ion removal of $79.9 \%$ and $86.0 \%$ for $\mathrm{Zn}^{+2}$ and $\mathrm{Cu}^{+2}$, respectively, was attained using $\mathrm{Fe}_{2} \mathrm{O}_{3}$-EC. EC biochar attained a maximum adsorption efficiency of $76.9 \%$ and $72.9 \%$ for $\mathrm{Zn}^{+2}$ and $\mathrm{Cu}^{+2}$, respectively. An increase in metal adsorption with increasing biomass is attributed to enhanced biosorption sites. A constant percentage for 


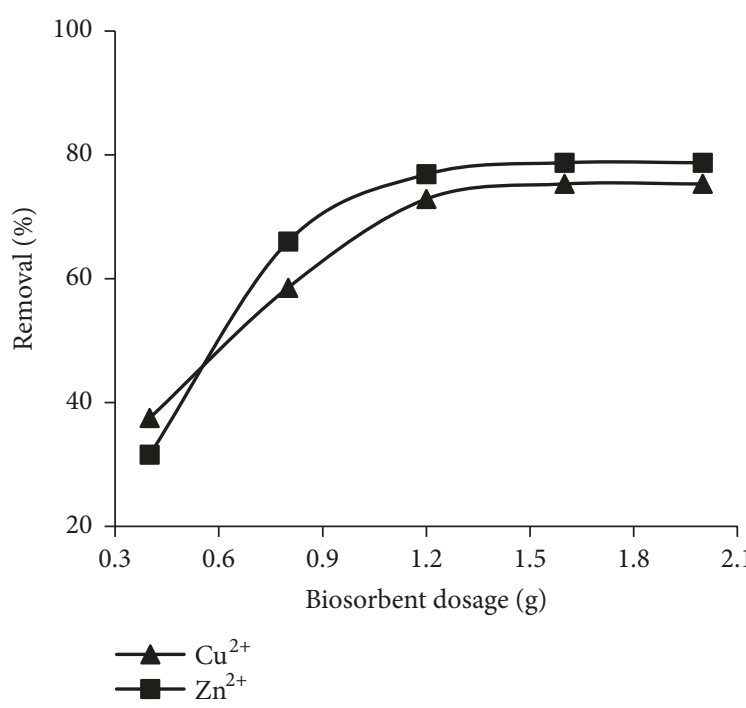

(a)

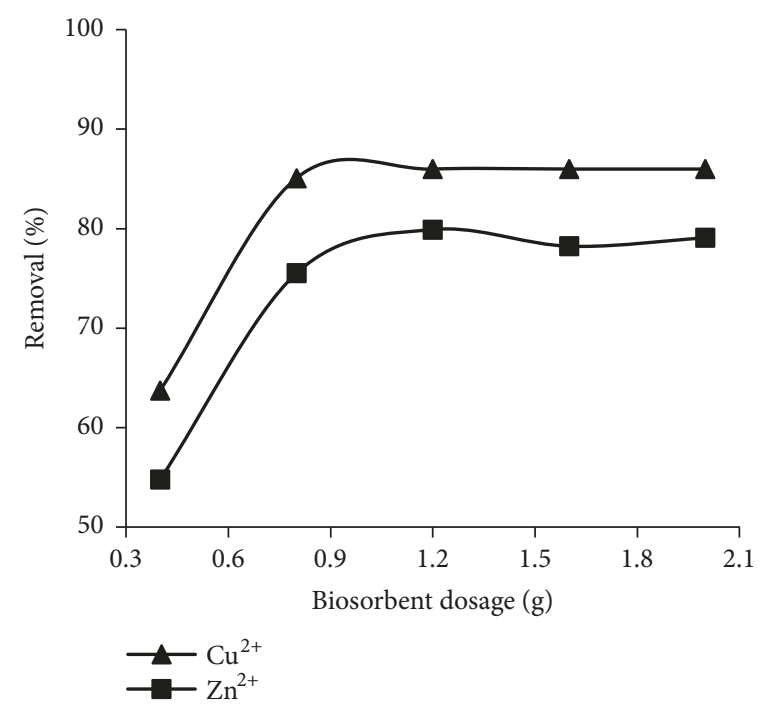

(b)

FIgURE 7: Effect of biosorbent dosage on metal ion removal using (a) EC and (b) $\mathrm{Fe}_{2} \mathrm{O}_{3}$-EC.

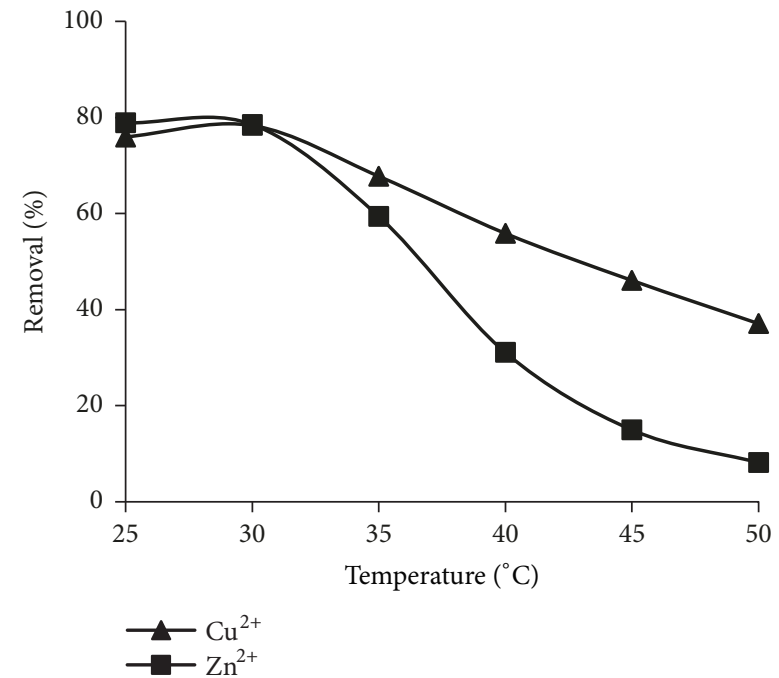

(a)

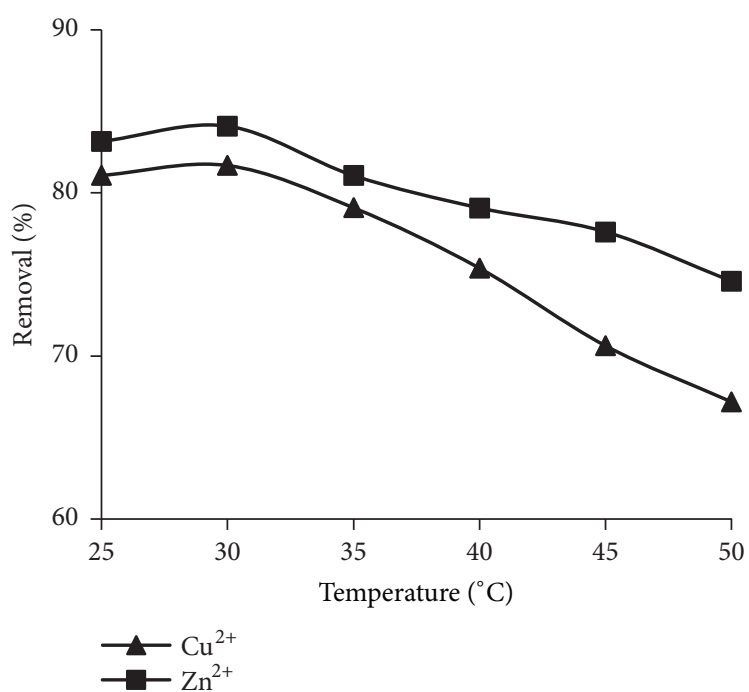

(b)

Figure 8: Effect of solution temperature on metal ion removal using (a) EC and (b) $\mathrm{Fe}_{2} \mathrm{O}_{3}$-EC.

metal ion removal beyond $1.2 \mathrm{~g}$ was due to overcrowding of biosorbent particles as a result of excessive biochar dosage leading to overlapping of adsorption sites.

3.2.5. Effect of Temperature. The effect of solution temperature on metal ion adsorption on the biosorbents is shown in Figure 8. The optimum temperature for metal ion adsorption was in the $25-30^{\circ} \mathrm{C}$ range. As the temperature was raised beyond $30^{\circ} \mathrm{C}$ metal ion sorption decreased. This could be attributed to degrading stability of adsorption sites with increasing temperature. High agglomeration rates experienced by EC at elevated temperature drastically reduced its sorption efficiency. The ability to withstand harsh temperature conditions by the iron oxide particles contributed to the resilience demonstrated by $\mathrm{Fe}_{2} \mathrm{O}_{3}$-EC.

3.3. Adsorption Isotherms. Adsorption isotherms play a fundamental role in predicting the nature of adsorbate-adsorbent interactions. Such studies help in designing adsorption systems for industrial applications since they provide data for maximum adsorption capacities of adsorbents [52]. Freundlich [53] and Langmuir [54] isotherms were applied in this study to interpret experimental data. The linearized form of the Langmuir isotherm (Figure 9) is represented by the following equation:

$$
\frac{1}{\mathrm{q}_{\mathrm{e}}}=\frac{1}{\mathrm{~K}_{\mathrm{L}} \mathrm{q}_{\max } \mathrm{C}_{\mathrm{e}}}+\frac{1}{\mathrm{q}_{\max }}
$$


TABLE 2: Langmuir and Freundlich constants for the metal ions adsorption on $\mathrm{Fe}_{2} \mathrm{O}_{3}$-EC.

\begin{tabular}{|c|c|c|c|c|c|c|c|}
\hline \multirow[t]{2}{*}{ Adsorbent } & \multirow[t]{2}{*}{ Adsorbate } & \multicolumn{3}{|c|}{ Langmuir } & \multicolumn{3}{|c|}{ Freundlich } \\
\hline & & $\begin{array}{c}\mathrm{q}_{\max } \\
\left(\mathrm{mg} \mathrm{g}^{-1}\right)\end{array}$ & $\begin{array}{c}\mathrm{K}_{\mathrm{L}} \\
\left(\mathrm{L} \mathrm{mg}^{-1}\right)\end{array}$ & $\mathrm{R}^{2}$ & $\begin{array}{c}\mathrm{K}_{\mathrm{F}} \\
\left(\mathrm{mg} \mathrm{g}^{-1}\right)\end{array}$ & $\mathrm{n}$ & $\mathrm{R}^{2}$ \\
\hline \multirow{2}{*}{$\mathrm{Fe}_{2} \mathrm{O}_{3}-\mathrm{EC}$} & $\mathrm{Cu}^{2+}$ & 3.53 & 5.916 & 0.998 & 3.31 & 1.69 & 0.987 \\
\hline & $\mathrm{Zn}^{2+}$ & 9.42 & 0.314 & 0.995 & 3.85 & 1.12 & 0.907 \\
\hline \multirow{2}{*}{$\mathrm{EC}$} & $\mathrm{Cu}^{2+}$ & 2.06 & 6.83 & 0.980 & 2.58 & 1.99 & 0.978 \\
\hline & $\mathrm{Zn}^{2+}$ & 5.99 & 5.71 & 0.992 & 5.89 & 1.53 & 0.966 \\
\hline
\end{tabular}

TABLE 3: Thermodynamic parameters derived from Vant Hoff's plots.

\begin{tabular}{|c|c|c|c|c|c|c|c|c|c|}
\hline \multicolumn{10}{|c|}{$\Delta \mathrm{G}^{\mathrm{o}}(\mathrm{kJ} / \mathrm{mol})$} \\
\hline \multicolumn{2}{|c|}{ Temperature $(\mathrm{K})$} & \multirow{2}{*}{298.15} & \multirow{2}{*}{303.15} & \multirow{2}{*}{308.15} & \multirow{2}{*}{313.15} & \multirow{2}{*}{318.15} & \multirow{2}{*}{323.15} & \multirow[t]{2}{*}{$\Delta \mathrm{S}^{\mathrm{o}}(\mathrm{kJ} / \mathrm{mol} / \mathrm{K})$} & \multirow[t]{2}{*}{$\Delta \mathrm{H}^{\mathrm{o}}(\mathrm{kJ} / \mathrm{mol})$} \\
\hline Adsorbent & Adsorbate & & & & & & & & \\
\hline \multirow{2}{*}{ EC } & $\mathrm{Cu}^{2+}$ & -9.571 & -8.044 & -6.517 & -4.991 & -3.464 & -1.937 & -0.305 & -100.608 \\
\hline & $\mathrm{Zn}^{2+}$ & -9.317 & -7.604 & -5.891 & -4.177 & -2.464 & -0.751 & -0.343 & -111.474 \\
\hline \multirow{2}{*}{$\mathrm{Fe}_{2} \mathrm{O}_{3}-\mathrm{EC}$} & $\mathrm{Cu}^{2+}$ & -6.370 & -8.018 & -9.667 & -11.315 & -12.964 & -14.612 & -0.330 & -91.928 \\
\hline & $\mathrm{Zn}^{2+}$ & -8.896 & -8.569 & -8.243 & -7.916 & -7.589 & -7.262 & -0.065 & -28.392 \\
\hline
\end{tabular}

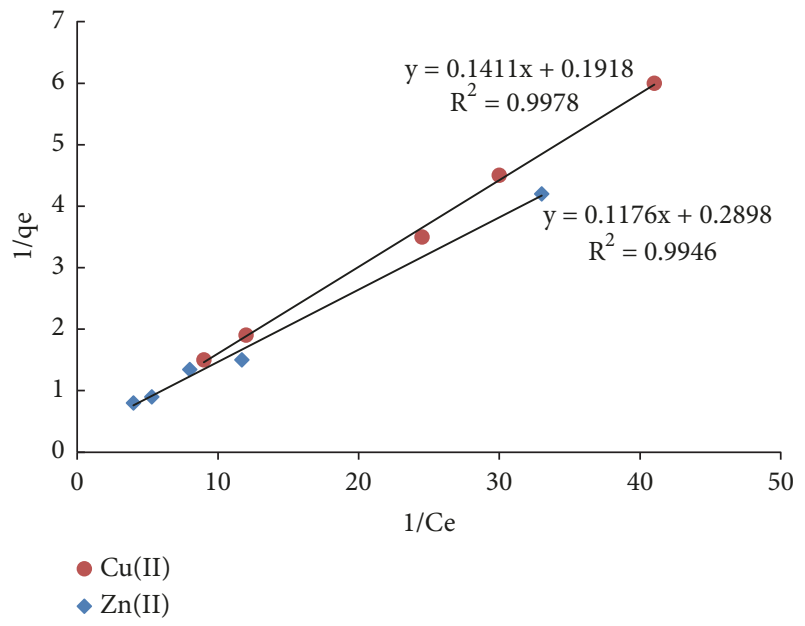

FIGURE 9: Langmuir isotherm for $\mathrm{Zn}^{+2}$ and $\mathrm{Cu}^{+2}$ biosorption on $\mathrm{Fe}_{2} \mathrm{O}_{3}$-EC.

where $\mathrm{q}_{\max }$ is the maximum adsorption capacity $\left(\mathrm{mg} \mathrm{g}^{-1}\right)$, $\mathrm{C}_{\mathrm{e}}\left(\mathrm{mg} \mathrm{L}^{-1}\right)$ is the equilibrium concentration, and $\mathrm{K}_{\mathrm{L}}$ is the Langmuir sorption constant $\left(\mathrm{L} \mathrm{mg}^{-1}\right)$ related to the free energy of sorption. A plot of $1 / q_{e}$ versus $1 / C_{e}$ produces a straight line with intercept $1 / q_{\max }$ and gradient $1 / \mathrm{K}_{\mathrm{L}} q_{\max }$ can be used to calculate $q_{\max }$ and $b$.

Linearized form for Freundlich isotherm is represented as

$$
\log \mathrm{q}_{\mathrm{e}}=\ln \mathrm{K}_{\mathrm{F}}+\frac{1}{\mathrm{n}} \ln \mathrm{C}_{\mathrm{e}}
$$

A plot of $\ln q_{e}$ versus $\ln C_{e}$ produces a straight line which is used to calculate Freundlich constants $K_{F}$ and $n$ from the intercept and slope, respectively.

Calculated values of Langmuir and Freundlich parameters for metal ion adsorption on $\mathrm{EC}$ and $\mathrm{Fe}_{2} \mathrm{O}_{3}$-EC are shown in Table 2. Based on $\mathrm{R}^{2}$ values presented, metal ion adsorption conformed more to the Langmuir isotherm. Maximum adsorption capacities for $\mathrm{Zn}^{+2}$ were higher than that of $\mathrm{Cu}^{+2}$ perhaps due to lower ionic radius of $\mathrm{Zn}^{2+}\left(0.71 \mathrm{~A}^{\circ}\right)$ than $\mathrm{Cu}^{2+}\left(0.73 \mathrm{~A}^{\circ}\right)$. The higher charge density of $\mathrm{Zn}^{2+}$ enhances the attraction for the biosorbent. The constant $n$ measures the deviation of biosorption from linearity (intensity of biosorption). The values of $\mathrm{n}$ greater than 1 for $\mathrm{Zn}^{2+}$ and $\mathrm{Cu}^{2+}$ ions indicate the favorable nature of biosorption [55].

3.4. Adsorption Thermodynamics. Thermodynamic parameters such as entropy change $(\Delta S)$, enthalpy change $(\Delta H)$, and the Gibbs free energy change $(\Delta G)$ are essential in the determination of industrial applications of adsorbents. $\Delta G^{0}$ is a critical thermodynamic parameter that provides adsorbent characteristics on the adsorption process [56]. These thermodynamic parameters were evaluated using the following equations:

$$
\begin{aligned}
\mathrm{K}_{\mathrm{T}} & =\frac{\mathrm{q}_{\mathrm{e}}}{\mathrm{C}_{\mathrm{e}}} \\
\ln \mathrm{K}_{\mathrm{T}} & =\frac{\Delta \mathrm{S}^{o}}{\mathrm{R}}+\frac{\Delta \mathrm{H}^{o}}{\mathrm{RT}} \\
\Delta \mathrm{G}^{o} & =\Delta \mathrm{H}^{o}-\mathrm{T} \Delta \mathrm{S}^{o}
\end{aligned}
$$

where $\mathrm{R}$ is the ideal gas constant, $\mathrm{T}$ is temperature in Kelvins, and $\mathrm{K}_{\mathrm{T}}$ is the thermodynamic equilibrium constant. The intercept and gradient derived from the Vant Hoff's (4) plot of $\ln \mathrm{K}_{\mathrm{T}}$ as an inverse function of temperature were used to calculate $\Delta \mathrm{H}^{\mathrm{o}}$ and $\Delta \mathrm{S}^{\mathrm{o}}$ shown in Table 3 . The calculated Gibbs free energy change values for the adsorption of $\mathrm{Cu}^{2+}$ and $\mathrm{Zn}^{2+}$ were all negative confirming the feasibility and spontaneity nature of the adsorption process. The negative $\Delta \mathrm{H}^{\mathrm{o}}$ values indicate the exothermic nature of the biosorption processes. The entropy change values for metal ions adsorption were negative indicating that the adsorption process involves an associative mechanism [57]. Metal ion adsorption leads to order through the formation of an activated complex between 
TABLE 4: First- and second-order kinetic parameters for metal ion adsorption on biochars.

\begin{tabular}{|c|c|c|c|c|c|c|c|c|}
\hline \multirow{2}{*}{ Adsorbent } & \multirow{2}{*}{ Ion } & \multirow[t]{2}{*}{$\mathrm{q}_{\exp }(\mathrm{mg} / \mathrm{g})$} & \multicolumn{3}{|c|}{ Pseudo- $1^{\text {st }}$ order } & \multicolumn{3}{|c|}{ Pseudo- $2^{\text {nd }}$ order } \\
\hline & & & $\mathrm{q}_{\mathrm{e}}(\mathrm{mg} / \mathrm{g})$ & $\mathrm{k}_{1}\left(\min ^{-1}\right)$ & $\mathrm{R}^{2}$ & $\mathrm{q}_{\mathrm{e}}(\mathrm{mg} / \mathrm{g})$ & $\mathrm{k}_{2}\left(\mathrm{~g} / \mathrm{mg} \min ^{-1}\right)$ & $\mathrm{R}^{2}$ \\
\hline \multirow{2}{*}{$\mathrm{EC}$} & $\mathrm{Cu}^{+2}$ & 2.46 & 2.30 & 0.045 & 0.974 & 2.39 & 0.18 & 0.982 \\
\hline & $\mathrm{Zn}^{+2}$ & 6.01 & 6.62 & 0.049 & 0.969 & 5.87 & 0.05 & 0.984 \\
\hline \multirow{2}{*}{$\mathrm{Fe}_{2} \mathrm{O}_{3}-\mathrm{EC}$} & $\mathrm{Cu}^{+2}$ & 3.25 & 1.41 & 0.091 & 0.598 & 3.24 & 0.05 & 0.998 \\
\hline & $\mathrm{Zn}^{+2}$ & 7.91 & 7.43 & 0.35 & 0.971 & 8.09 & 0.01 & 0.993 \\
\hline
\end{tabular}

TABLE 5: Adsorption efficiency of adsorbents after five desorption cycles.

\begin{tabular}{|c|c|c|c|c|}
\hline \multirow{3}{*}{$\mathrm{NaOH}$ concentration $(\mathrm{M})$} & \multicolumn{4}{|c|}{ Adsorption efficiency (\%) } \\
\hline & \multicolumn{2}{|c|}{$\mathrm{EC}$} & \multicolumn{2}{|c|}{$\mathrm{Fe}_{2} \mathrm{O}_{3}-\mathrm{EC}$} \\
\hline & $\mathrm{Cu}^{+2}$ & $\mathrm{Zn}^{+2}$ & $\mathrm{Cu}^{+2}$ & $\mathrm{Zn}^{+2}$ \\
\hline 0.10 & 73 & 75 & 87 & 88 \\
\hline 0.25 & 75 & 78 & 92 & 93 \\
\hline 0.50 & 69 & 70 & 81 & 82 \\
\hline
\end{tabular}

the adsorbate and adsorbent. The negative values of $\Delta S^{\circ}$ reflected that no significant change occurs in the internal structures of the adsorbent during adsorption.

3.5. Adsorption Kinetics. Adsorption kinetics provide essential information for determining the adsorption rate controlling mechanisms. Two frequently used integrated linearized kinetic models: Lagergren and Ho-McKay $(8)$ and $(9)[17,58]$ were used to analyse the experimental data. The parameters $\mathrm{q}_{\mathrm{t}}$ and $\mathrm{q}_{\mathrm{e}}\left(\mathrm{mg} \mathrm{g}^{-1}\right)$ are the respective adsorption capacities at time, $\mathrm{t}$, and equilibrium, $\mathrm{k}_{1}\left(\mathrm{~min}^{-1}\right)$ and $\mathrm{k}_{2}\left(\mathrm{~g} \mathrm{mg}^{-1} \min ^{-1}\right)$ are the Lagergren's pseudo $1^{\text {st }}$ - and Ho-McKay's $2^{\text {nd }}$-order constants, respectively.

$$
\begin{aligned}
\log \left(\mathrm{q}_{\mathrm{e}}-\mathrm{q}_{\mathrm{t}}\right) & =\log \mathrm{q}_{\mathrm{e}}-\frac{\mathrm{k}_{1} \mathrm{t}}{2.303} \\
\frac{\mathrm{t}}{\mathrm{q}_{\mathrm{t}}} & =\frac{1}{\mathrm{k}_{2} \mathrm{q}_{\mathrm{e}}^{2}}+\frac{\mathrm{t}}{\mathrm{q}_{\mathrm{e}}}
\end{aligned}
$$

Equation (8) hypothesise an adsorption rate that is proportional to the population of vacant sites whilst (9) is based on the hypothesis that the sorption rate is closely related to the square of the population of vacant sites. The biosorption kinetic parameters are shown in Table 4 . The coefficients of determination $\left(\mathrm{R}^{2}\right)$ for the pseudo-first-order on EC were 0.969 and 0.974 for $\mathrm{Zn}^{+2}$ and $\mathrm{Cu}^{+2}$, respectively. On the other hand, the correlation coefficient $\left(\mathrm{R}^{2}\right)$ values of the pseudosecond-order kinetic model on EC were 0.984 and 0.982 for $\mathrm{Zn}^{+2}$ and $\mathrm{Cu}^{+2}$ ions, respectively. Higher correlation coefficient values and good agreement between calculated $\left(\mathrm{q}_{\mathrm{e}}\right)$ and experimental $\left(\mathrm{q}_{\mathrm{exp}}\right)$ values indicate more applicability of the pseudo-second-order kinetic model for EC systems. The coefficients of determination for the pseudo-first-order on $\mathrm{Fe}_{2} \mathrm{O}_{3}$-EC were 0.971 and 0.598 for $\mathrm{Zn}^{+2}$ and $\mathrm{Cu}^{+2}$, respectively. The correlation coefficient values of the pseudosecond-order kinetic model were 0.998 and 0.993 for $\mathrm{Zn}^{+2}$ and $\mathrm{Cu}^{+2}$, respectively. Higher and good agreement between calculated and experimental values and high correlation coefficient values show that the pseudo-second-order kinetic model conforms to the $\mathrm{Fe}_{2} \mathrm{O}_{3}$-EC systems. Such kinetic data show that chemisorption was the rate limiting step in the uptake of the metal ions by the adsorbents.

3.6. Desorption and Reusability Studies. The reusability of adsorbents is important to achieve cost effective water treatment. Desorption studies help in the process design of systems by giving information on mechanisms and recovery of adsorbates from industrial wastewater and the adsorbent. Table 5 shows the adsorption efficiency of $\mathrm{Fe}_{2} \mathrm{O}_{3}$-EC and EC after five desorption cycles. The maximum desorption was attained at $0.25 \mathrm{M} \mathrm{NaOH}$. The adsorption efficiency of $\mathrm{Fe}_{2} \mathrm{O}_{3}$-EC remained above $80 \%$ in all studies indicative of its high reusability capacity. This data suggests that $\mathrm{Fe}_{2} \mathrm{O}_{3}$ $\mathrm{EC}$ is cost effective in the treatment of water containing low concentrations (less than $15 \mathrm{mg} \mathrm{L}^{-1}$ ) of $\mathrm{Zn}^{+2}$ and $\mathrm{Cu}^{+2}$.

\section{Conclusion}

In this study $\mathrm{Fe}_{2} \mathrm{O}_{3}$-EC prepared by coprecipitation of ferric and ferrous salts on water hyacinth powder followed by slow pyrolysis has demonstrated great potential in the removal of aqueous metal ion pollutants. This approach provided a useful way to manage this highly problematic invasive species. Metal ion adsorption onto the biosorbents conformed to the Langmuir isotherm. Chemical modification of hyacinth biochar significantly improved metal ion adsorption capacity. The metal ions adsorption onto the adsorbents best fit pseudo $2^{\text {nd }}$-order kinetics. Thermodynamic parameters showed that the biosorption process was feasible, spontaneous, and exothermic. $\mathrm{Fe}_{2} \mathrm{O}_{3}$-EC exhibited metal ion adsorption efficiency above $80 \%$ in all studies indicative of its high reusability capacity.

This study focused on sorption of single metal ions from spiked solution. There is need to assess the competitive sorption of metal ions by hyacinth biochar in natural waters. 
Wastewater is more complicated than simulated water used in this study. To ensure suitability of hyacinth biochar in treating metal ions in wastewater, the use of actual contaminated water for studies should be done. To further support field application, future studies should address factors related to metal ion removal efficiency such as application rate, modification of biochar using other minerals, dosing, regeneration, and disposal of metal ions adsorbed biochars.

\section{Data Availability}

The data in form of tables and graphs used to support the findings of this study entitled: "Removal of $\mathrm{Zn}$ (II) and $\mathrm{Cu}$ (II) Ions from Industrial Wastewaters Using Magnetic Biochar Derived from Water Hyacinth" are available from the corresponding author upon request.

\section{Conflicts of Interest}

The authors declare that they have no conflicts of interest.

\section{References}

[1] R. Reza and G. Singh, "Heavy metal contamination and its indexing approach for river water," International Journal of Environmental Science and Technology, vol. 7, no. 4, pp. 785-792, 2010.

[2] M. A. Barakat, "New trends in removing heavy metals from industrial wastewater," Arabian Journal of Chemistry, vol. 4, no. 4, pp. 361-377, 2011.

[3] Q.-Q. Chi, G.-W. Zhu, and A. Langdon, "Bioaccumulation of heavy metals in fishes from Taihu Lake, China," Journal of Environmental Sciences, vol. 19, no. 12, pp. 1500-1504, 2007.

[4] A. Heikens, W. J. G. M. Peijnenburg, and A. J. Hendriks, "Bioaccumulation of heavy metals in terrestrial invertebrates," Environmental Pollution, vol. 113, no. 3, pp. 385-393, 2001.

[5] N. Adhoum, L. Monser, N. Bellakhal, and J.-E. Belgaied, “Treatment of electroplating wastewater containing $\mathrm{Cu}^{2+}, \mathrm{Zn}^{2+}$ and $\mathrm{Cr}(\mathrm{VI})$ by electrocoagulation," Journal of Hazardous Materials, vol. 112, no. 3, pp. 207-213, 2004.

[6] F. Fu and Q. Wang, "Removal of heavy metal ions from wastewaters: a review," Journal of Environmental Management, vol. 92, no. 3, pp. 407-418, 2011.

[7] M. Hua, S. Zhang, B. Pan, W. Zhang, L. Lv, and Q. Zhang, "Heavy metal removal from water/wastewater by nanosized metal oxides: a review," Journal of Hazardous Materials, vol. 211212, pp. 317-331, 2012.

[8] T. A. Kurniawan, G. Y. S. Chan, W.-H. Lo, and S. Babel, "Physico-chemical treatment techniques for wastewater laden with heavy metals," Chemical Engineering Journal, vol. 118, no. 1-2, pp. 83-98, 2006.

[9] U. Guyo, J. Mhonyera, and M. Moyo, "Pb(II) adsorption from aqueous solutions by raw and treated biomass of maize stover-a comparative study," Process Safety and Environmental Protection, vol. 93, pp. 192-200, 2015.

[10] C. K. Geethamani, S. T. Ramesh, R. Gandhimathi, and P. V. Nidheesh, "Alkali-treated fly ash for the removal of fluoride from aqueous solutions," Desalination and Water Treatment, vol. 52, no. 19-21, pp. 3466-3476, 2014.
[11] C. K. Jain, D. S. Malik, and A. K. Yadav, "Applicability of plant based biosorbents in the removal of heavy metals: a review," Environmental Processes, vol. 3, no. 2, pp. 495-523, 2016.

[12] W. S. Wan Ngah and M. A. K. M. Hanafiah, "Removal of heavy metal ions from wastewater by chemically modified plant wastes as adsorbents: a review," Bioresource Technology, vol. 99, no. 10, pp. 3935-3948, 2008.

[13] W. Song, J. Liang, T. Wen et al., "Accumulation of Co(II) and $\mathrm{Eu}(\mathrm{III})$ by the mycelia of Aspergillus niger isolated from radionuclide-contaminated soils," Chemical Engineering Journal, vol. 304, pp. 186-193, 2016.

[14] S. A. Cumberland, S. A. Wilson, B. Etschmann et al., "Rapid immobilisation of U(VI) by eucalyptus bark: adsorption without reduction," Applied Geochemistry, vol. 96, pp. 1-10, 2018.

[15] H. E. Reynel-Avila, D. I. Mendoza-Castillo, A. A. Olumide, and A. Bonilla-Petriciolet, "A survey of multi-component sorption models for the competitive removal of heavy metal ions using bush mango and flamboyant biomasses," Journal of Molecular Liquids, vol. 224, pp. 1041-1054, 2016.

[16] M. J. V. Thamilarasi, P. Anilkumar, C. Theivarasu, and M. V. Sureshkumar, "Removal of vanadium from wastewater using surface-modified lignocellulosic material," Environmental Science and Pollution Research, vol. 25, no. 26, pp. 26182-26191, 2018.

[17] M. Moyo, U. Guyo, G. Mawenyiyo, N. P. Zinyama, and B. C. Nyamunda, "Marula seed husk (Sclerocarya birrea) biomass as a low cost biosorbent for removal of $\mathrm{Pb}$ (II) and $\mathrm{Cu}$ (II) from aqueous solution," Journal of Industrial and Engineering Chemistry, vol. 27, pp. 126-132, 2015.

[18] X. Xu, X. Cao, and L. Zhao, "Comparison of rice husk- and dairy manure-derived biochars for simultaneously removing heavy metals from aqueous solutions: role of mineral components in biochars," Chemosphere, vol. 92, no. 8, pp. 955-961, 2013.

[19] P. Regmi, J. L. Garcia Moscoso, S. Kumar, X. Cao, J. Mao, and G. Schafran, "Removal of copper and cadmium from aqueous solution using switchgrass biochar produced via hydrothermal carbonization process," Journal of Environmental Management, vol. 109, pp. 61-69, 2012.

[20] A. M. Villamagna and B. R. Murphy, "Ecological and socioeconomic impacts of invasive water hyacinth (eichhornia crassipes): a review," Freshwater Biology, vol. 55, no. 2, pp. 282-298, 2010.

[21] A. Malik, "Environmental challenge vis a vis opportunity: the case of water hyacinth," Environment International, vol. 33, no. 1, pp. 122-138, 2007.

[22] D. D. C. Bicudo, B. M. Fonseca, L. M. Bini, L. O. Crossetti, C. E. D. M. Bicudo, and T. Araújo-Jesus, "Undesirable sideeffects of water hyacinth control in a shallow tropical reservoir," Freshwater Biology, vol. 52, no. 6, pp. 1120-1133, 2007.

[23] S. Patel, "Threats, management and envisaged utilizations of aquatic weed Eichhornia crassipes: an overview," Reviews in Environmental Science and Bio/Technology, vol. 11, no. 3, pp. 249-259, 2012.

[24] E. Kateregga and T. Sterner, "Indicators for an invasive species: water hyacinths in Lake Victoria," Ecological Indicators, vol. 7, no. 2, pp. 362-370, 2007.

[25] J. A. Coetzee and M. P. Hill, "The role of eutrophication in the biological control of water hyacinth, Eichhornia crassipes, in South Africa," BioControl, vol. 57, no. 2, pp. 247-261, 2012.

[26] S. Ram and M. K. Moolani, "Herbicidal weed control of water hyacinth under semi-arid conditions," Pestology, vol. 24, no. 2, pp. 69-71, 2000. 
[27] Y. Zhang, M. Yang, X.-M. Dou, H. He, and D.-S. Wang, "Arsenate adsorption on an Fe-Ce bimetal oxide adsorbent: role of surface properties," Environmental Science \& Technology, vol. 39, no. 18, pp. 7246-7253, 2005.

[28] S. Rezania, M. Ponraj, A. Talaiekhozani et al., "Perspectives of phytoremediation using water hyacinth for removal of heavy metals, organic and inorganic pollutants in wastewater," Journal of Environmental Management, vol. 163, pp. 125-133, 2015.

[29] S. Kloss, F. Zehetner, A. Dellantonio et al., "Characterization of slow pyrolysis biochars: effects of feedstocks and pyrolysis temperature on biochar properties," Journal of Environmental Quality, vol. 41, no. 4, pp. 990-1000, 2012.

[30] X. Cao and W. Harris, "Properties of dairy-manure-derived biochar pertinent to its potential use in remediation," Bioresource Technology, vol. 101, no. 14, pp. 5222-5228, 2010.

[31] X. Xu, X. Cao, L. Zhao, H. Wang, H. Yu, and B. Gao, "Removal of $\mathrm{Cu}, \mathrm{Zn}$, and $\mathrm{Cd}$ from aqueous solutions by the dairy manurederived biochar," Environmental Science and Pollution Research, vol. 20, no. 1, pp. 358-368, 2013.

[32] Y. Yao, B. Gao, M. Inyang et al., "Removal of phosphate from aqueous solution by biochar derived from anaerobically digested sugar beet tailings," Journal of Hazardous Materials, vol. 190, no. 1-3, pp. 501-507, 2011.

[33] M. I. Inyang, B. Gao, Y. Yao et al., "A review of biochar as a low-cost adsorbent for aqueous heavy metal removal," Critical Reviews in Environmental Science and Technology, vol. 46, no. 4, pp. 406-433, 2016.

[34] D. Mohan, A. Sarswat, Y. S. Ok, and C. U. Pittman, "Organic and inorganic contaminants removal from water with biochar, a renewable, low cost and sustainable adsorbent-a critical review," Bioresource Technology, vol. 160, pp. 191-202, 2014.

[35] R. Cai, X. Wang, X. Ji, B. Peng, C. Tan, and X. Huang, "Phosphate reclaim from simulated and real eutrophic water by magnetic biochar derived from water hyacinth," Journal of Environmental Management, vol. 187, pp. 212-219, 2017.

[36] F. Zhang, X. Wang, J. Xionghui, and L. Ma, "Efficient arsenate removal by magnetite-modified water hyacinth biochar," Environmental Pollution, vol. 216, pp. 575-583, 2016.

[37] F. Zhang, X. Wang, D. Yin et al., "Efficiency and mechanisms of Cd removal from aqueous solution by biochar derived from water hyacinth (Eichornia crassipes)," Journal of Environmental Management, vol. 153, pp. 68-73, 2015.

[38] J. Yu, C. Jiang, Q. Guan et al., "Enhanced removal of Cr(VI) from aqueous solution by supported $\mathrm{ZnO}$ nanoparticles on biochar derived from waste water hyacinth," Chemosphere, vol. 195, pp. 632-640, 2018.

[39] B. Chen, Z. Chen, and S. Lv, "A novel magnetic biochar efficiently sorbs organic pollutants and phosphate," Bioresource Technology, vol. 102, no. 2, pp. 716-723, 2011.

[40] W. Suliman, J. B. Harsh, N. I. Abu-Lail, A.-M. Fortuna, I. Dallmeyer, and M. Garcia-Perez, "Influence of feedstock source and pyrolysis temperature on biochar bulk and surface properties," Biomass \& Bioenergy, vol. 84, pp. 37-48, 2016.

[41] R. Li, J. J. Wang, B. Zhou et al., "Simultaneous capture removal of phosphate, ammonium and organic substances by $\mathrm{MgO}$ impregnated biochar and its potential use in swine wastewater treatment," Journal of Cleaner Production, vol. 147, pp. 96-107, 2017.

[42] B. L. Chen, D. D. Zhou, and L. Z. Zhu, "Transitional adsorption and partition of nonpolar and polar aromatic contaminants by biochars of pine needles with different pyrolytic temperatures,"
Environmental Science \& Technology, vol. 42, no. 14, pp. 5137$5143,2008$.

[43] L.-G. Yan, K. Yang, R.-R. Shan et al., "Kinetic, isotherm and thermodynamic investigations of phosphate adsorption onto core-shell Fe3O4@LDHs composites with easy magnetic separation assistance," Journal of Colloid and Interface Science, vol. 448, pp. 508-516, 2015.

[44] R. A. Anayurt, A. Sari, and M. Tuzen, "Equilibrium, thermodynamic and kinetic studies on biosorption of $\mathrm{Pb}$ (II) and $\mathrm{Cd}(\mathrm{II})$ from aqueous solution by macrofungus (Lactarius scrobiculatus) biomass," Chemical Engineering Journal, vol. 151, no. 1-3, pp. 255-261, 2009.

[45] D. H. K. Reddy and S. M. Lee, "Synthesis and characterisation of chitosan ligand for the removal of copper from aqueous media," Journal of Applied Polymer Science, vol. 130, pp. 4542-4550, 2013.

[46] S. Wang, B. Gao, A. R. Zimmerman et al., "Removal of arsenic by magnetic biochar prepared from pinewood and natural hematite," Bioresource Technology, vol. 175, pp. 391-395, 2015.

[47] M. Mohapatra, L. Mohapatra, P. Singh, S. Anand, and B. Mishra, "A comparative study on $\mathrm{Pb}(\mathrm{II}), \mathrm{Cd}(\mathrm{II}), \mathrm{Cu}(\mathrm{II}), \mathrm{Co}(\mathrm{II})$ adsorption from single and binary aqueous solutions on additive assisted nano-structured goethite," International Journal of Engineering, Science and Technology, vol. 2, no. 8, pp. 89-94, 2010.

[48] S.-T. Song, N. Saman, K. Johari, and H. Mat, "Removal of $\mathrm{Hg}$ (II) from aqueous solution by adsorption using raw and chemically modified rice straw as novel adsorbents," Industrial \& Engineering Chemistry Research, vol. 52, no. 36, pp. 1309213101, 2013.

[49] A. M. Awwad and N. M. Salem, "Biosorption of copper(II) and lead(II) ions from aqueous solutions by modified loquat (Eriobotrya japonica) leaves (MLL)," Journal of Chemical Engineering and Materials Science, vol. 3, no. 1, pp. 7-17, 2012.

[50] D. Kavitha and C. Namasivayam, "Experimental and kinetic studies on methylene blue adsorption by coir pith carbon," Bioresource Technology, vol. 98, no. 1, pp. 14-21, 2007.

[51] A. Sari and M. Tuzen, "Biosorption of cadmium(II) from aqueous solution by red algae (Ceramium virgatum): equilibrium, kinetic and thermodynamic studies," Journal of Hazardous Materials, vol. 157, no. 2-3, pp. 448-454, 2008.

[52] E. Igberase, P. Osifo, and A. Ofomaja, “The adsorption of copper (II) ions by polyaniline graft chitosan beads from aqueous solution: equilibrium, kinetic and desorption studies," Journal of Environmental Chemical Engineering (JECE), vol. 2, no. 1, pp. 362-369, 2014.

[53] H. M. F. Freundlich, "Over the adsorption in solution," The Journal of Physical Chemistry A, vol. 57, pp. 385-470, 1906.

[54] I. Langmuir, "The constitution and fundamental properties of solids and liquids, Part I: solids," Journal of the American Chemical Society, vol. 38, no. 2, pp. 2221-2295, 1916.

[55] L. Wang, J. Zhang, R. Zhao, Y. Li, C. Li, and C. Zhang, "Adsorption of $\mathrm{Pb}(\mathrm{II})$ on activated carbon prepared from Polygonum orientale Linn.: kinetics, isotherms, $\mathrm{pH}$, and ionic strength studies," Bioresource Technology, vol. 101, no. 15, pp. 5808-5814, 2010.

[56] D. Ruziwa, N. Chaukura, W. Gwenzi, and I. Pumure, "Removal of $\mathrm{Zn} 2+$ and $\mathrm{Pb} 2+$ ions from aqueous solution using sulphonated waste polystyrene," Journal of Environmental Chemical Engineering (JECE), vol. 3, no. 4, pp. 2528-2537, 2015.

[57] C.-F. Lin, K.-S. Chang, C.-W. Tsay, D.-Y. Lee, S.-L. Lo, and T. Yasunaga, "Adsorption mechanism of Gallium(III) and 
Indium(III) onto $\gamma$-Al2O3," Journal of Colloid and Interface Science, vol. 188, no. 1, pp. 201-208, 1997.

[58] A. E. Rodrigues and C. M. Silva, "What's wrong with Lagergreen pseudo first order model for adsorption kinetics?" Chemical Engineering Journal, vol. 306, pp. 1138-1142, 2016. 


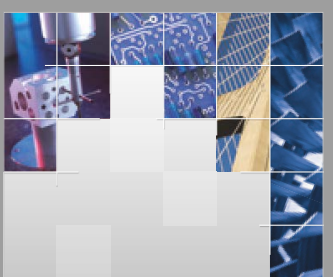

\section{Enfincering}
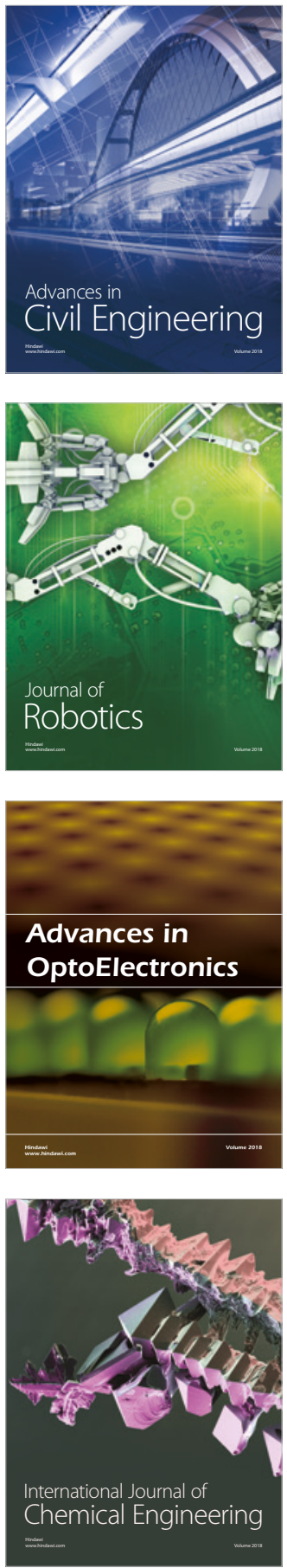

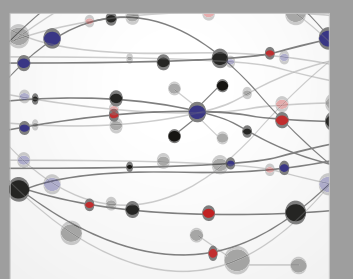

\section{Rotating \\ Machinery}

The Scientific World Journal

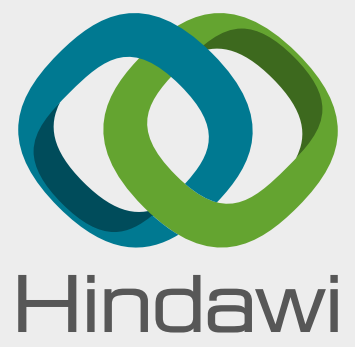

Submit your manuscripts at

www.hindawi.com
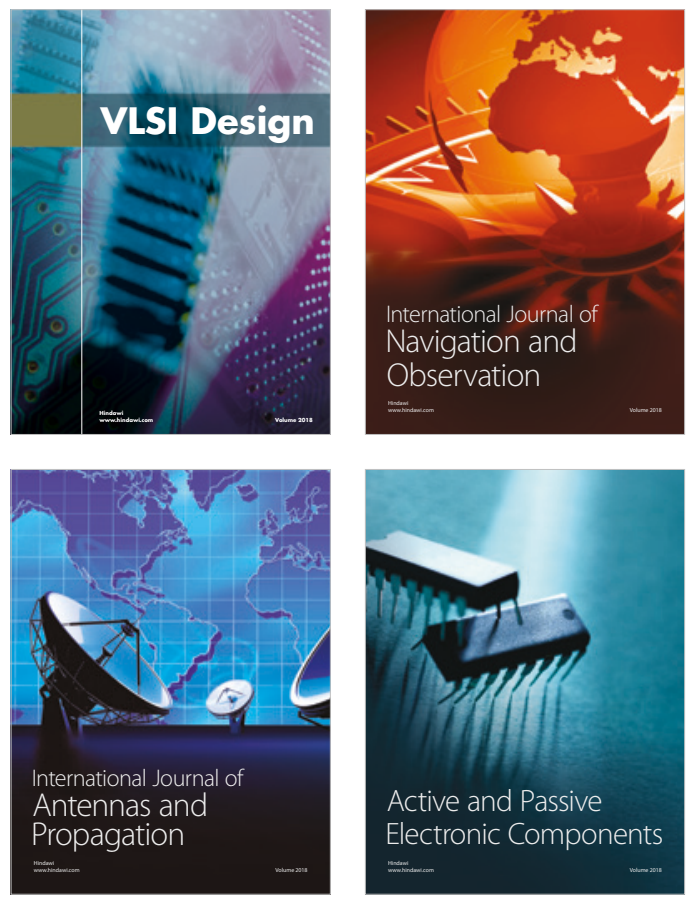
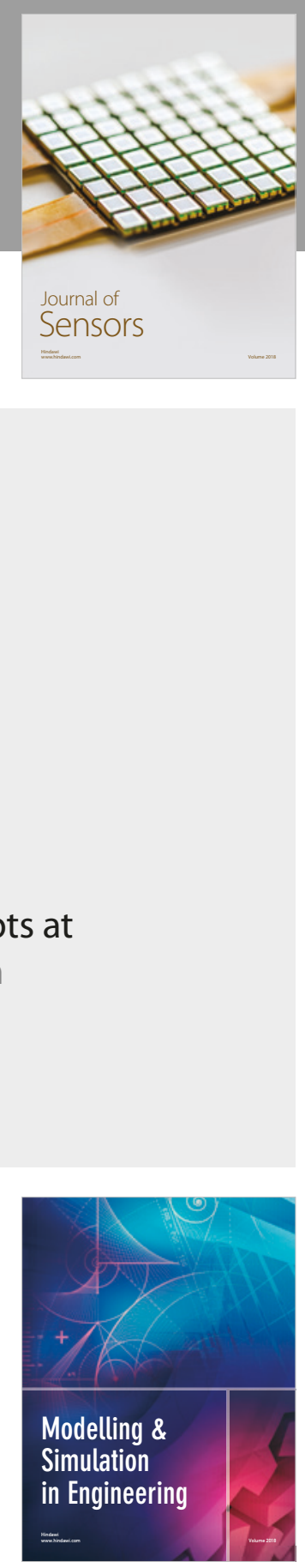

\section{Advances \\ Multimedia}
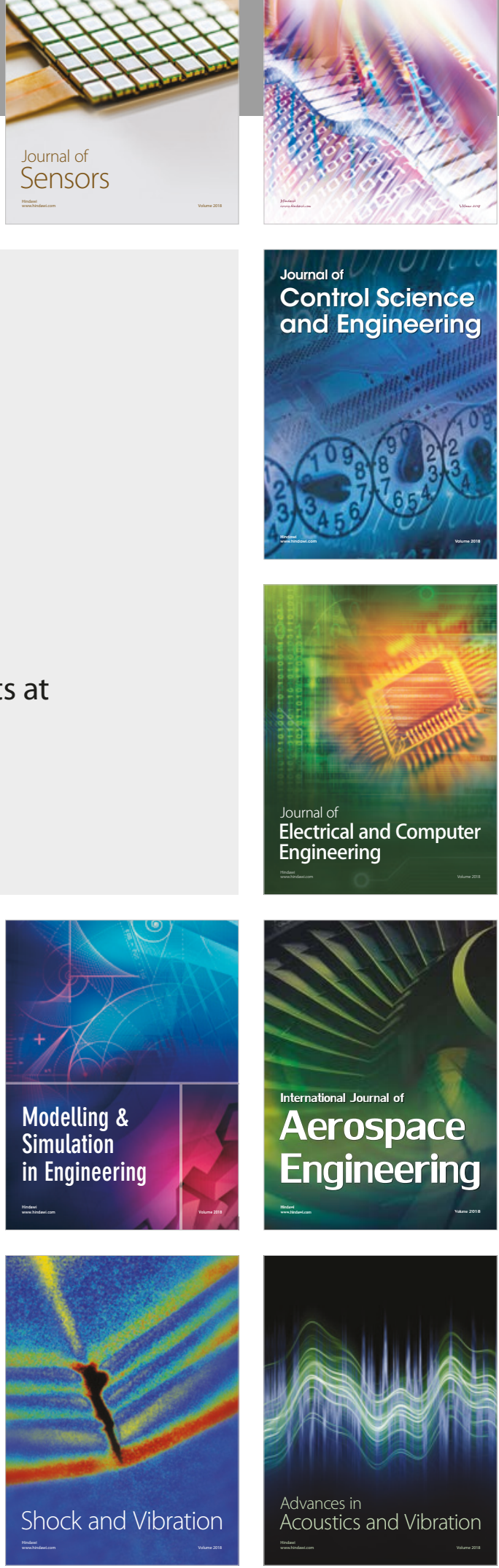